\title{
Malaria Parasite Diagnosis using Fuzzy Logic
}

\author{
Khalid Alsir Mohamed ${ }^{1}$, Eltahir Mohamed Hussein ${ }^{2}$ \\ ${ }^{1}$ Department of Control Engineering, Al-Neelain University, Khartoum, Sudan \\ ${ }^{2}$ Department of Biomedical Engineering College of Engineering, Sudan University of Science and Technology, Khartoum, Sudan
}

\begin{abstract}
Malaria is one of the important tropical infectious diseases. The incidence of malaria worldwide is estimated to be $300-600$ million clinical cases each year with a mortality of between one and three million people worldwide annually. The accuracy and timely diagnosis of malaria infection is essential if severe complications and mortality are to be reduced by earlier specific anti-malaria treatment. This review details the methods for the laboratory diagnosis of malaria infection.
\end{abstract}

Keywords: Fuzzy Logic, MATLAB, Pulse rate, BMI, Algorithm

\section{Introduction}

The important thing in people life is its life and health. So to make it secure and to protect for different type of diseases using a new technology here [1]. Develop certain algorithm which should help full in identifying of more serious diseases like Malaria. [2]. Identification of malaria at early stage will be helpful as its effect increasing drastically and cause great harm to people life [3]. Malaria is due to imbalance (increase) of amount of parasites in the patient's blood and an indicator for the degree of infection [4].

Malaria is caused by a blood parasite named Plasmodium spp [5]. It affects at least 300 to 600 million people every year and causes an estimated 3 million deaths [6].

Diagnosis and medicine of it is necessary. So for medication should start at proper time is very important to identify the diseases very high, fast and accurate [7].

In this technique use the blood cell images to get out the patients is malaria effected or not effected [8].

We used the statistical characteristics of image like (Standard deviation, kurtosis and Energy) which will overcome the mistake of not clearly visible boundaries of cells [9] . Classification here implemented algorithms which on by discussed and have different advantages over increasing in performance [10].

\section{Fuzzy Logic System}

It is reasoning, think and infer that recognizes and uses the real world phenomenon that everything is a matter of degree [11]. The theory of fuzzy logic encompasses a mathematically strength to taken the uncertainty associated with people cognitive processes [12]. It is a methodology that taken and uses the concept of fuzziness in a computationally effective manner. Using a fuzzy approach, the transition between terms can be gradual, binary, all, or none, selections should be the extremely ends of a continual. It view of the world was put into operation for computational purposes through the use of fuzzy sets. Fuzzy sets variable terms, and definitions can be thought in terms of sets and set theory [13].

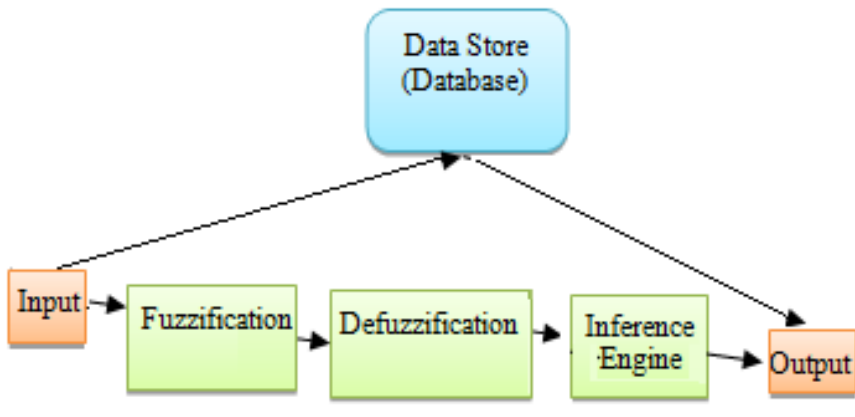

\section{Methodology}

Data Collection: Is a case study Literature survey, observation, view, patients' folder studies and consultation were used for gather data to unearthly the hospitals need also establish the requirement of the decide on inputs and outputs variables, create membership function, and design fuzzy logic decision matrices. Purposive sampling method used to select three medical patients, random sampling method used for the select of patients.

Data-store Contains the Knowledge Base and the Database. The Knowledge Base taken from the medical experts and malaria references review. The Knowledge Base Contains of a set of condition (IF and THEN) in the decision matrices constructed using logical gate (AND) operator and forward chaining and storing in data-store for references by the inference engine. Patients' are a health history for future reference.

Input data Main goal is receiving data into the system using inputs (i.e. keyboard) technology. The users reads the exact numbers taken from the instruments for measuring the patients' weight, height, temperature and pulse rate in BPM respectively, kilograms, Celsius and meters. The converted intensity values are determined in one hundred percent and entered.

Fuzzification The crisp input data values are converted to membership degrees, by applying the correspond of membership functions. Mathematically. $\mathrm{X}=$ fuzzifier (x0)

Where xo is a crisp input value, $\mathrm{X}$ is the corresponding fuzzy logic set, and fuzzifier represent a fuzzification function. 


\section{International Journal of Science and Research (IJSR) \\ ISSN (Online): 2319-7064 \\ Index Copernicus Value (2013): 6.14 | Impact Factor (2015): 6.391}

Each fuzzy logic input variable is fuzzified using 3 values named (low, medium and high). Triangular membership function is used. Membership function of symptom input variables named (temperature, BMI and Pulse rate) generated from MATLAB.

Inference Engine Fuzzified input is then was match with the syntax and a set of fuzzy logic actions are generated. Sampling of the rules is shown below:

1)If min temperature, BMI and pulse rate are (low). Then parasite diagnosis equal (malaria free) and the treatment equal (discharge patients without medication).

2)If min temperature and BMI are (medium), pulse rate is (low) Then the parasite diagnosis equal (uncomplicated malaria) and treatment equal (Articulate tablet or Amodiaquine syrup).

Defuzzification Is to generate the values that should be representative of the output from the inference engine.

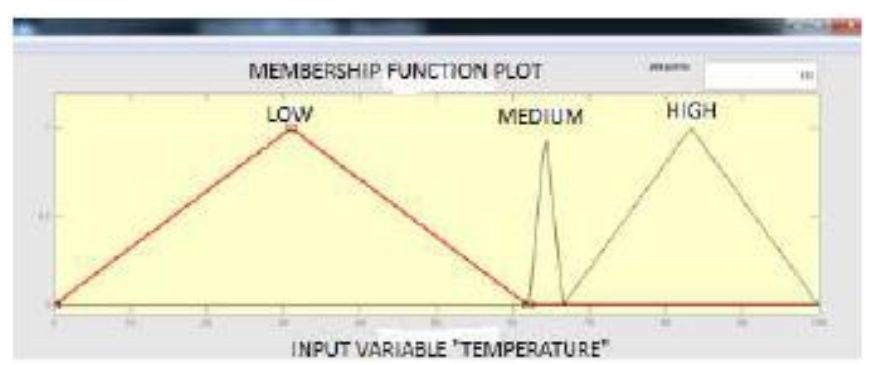

Figure 1: Input: temperature

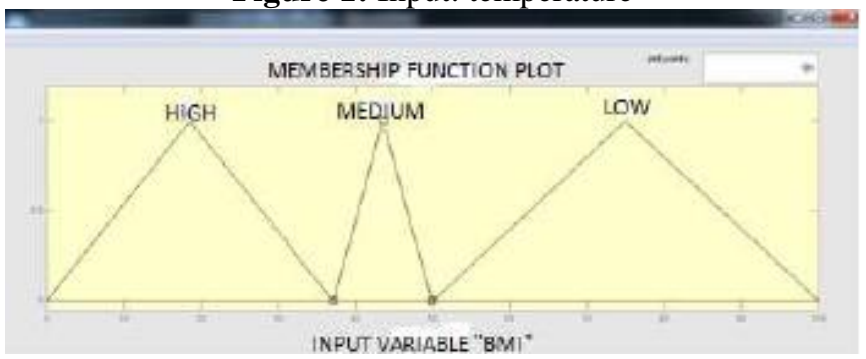

Figure 2: Input: BMI

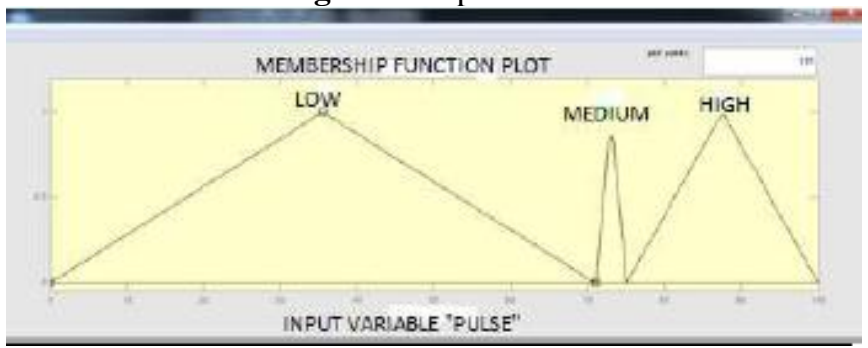

Figure 3: Input pulse

Centre- of -Gravity method is used. This is because Centreof -Gravity defuzzification method is simple and requires Less computation effort compared to MOM, MAX, HD and Centre- of -Gravity [13].

Output of the system there are two outputs in a system, named membership function of parasite diagnosis and treatment output variables are view in figures 4 below.

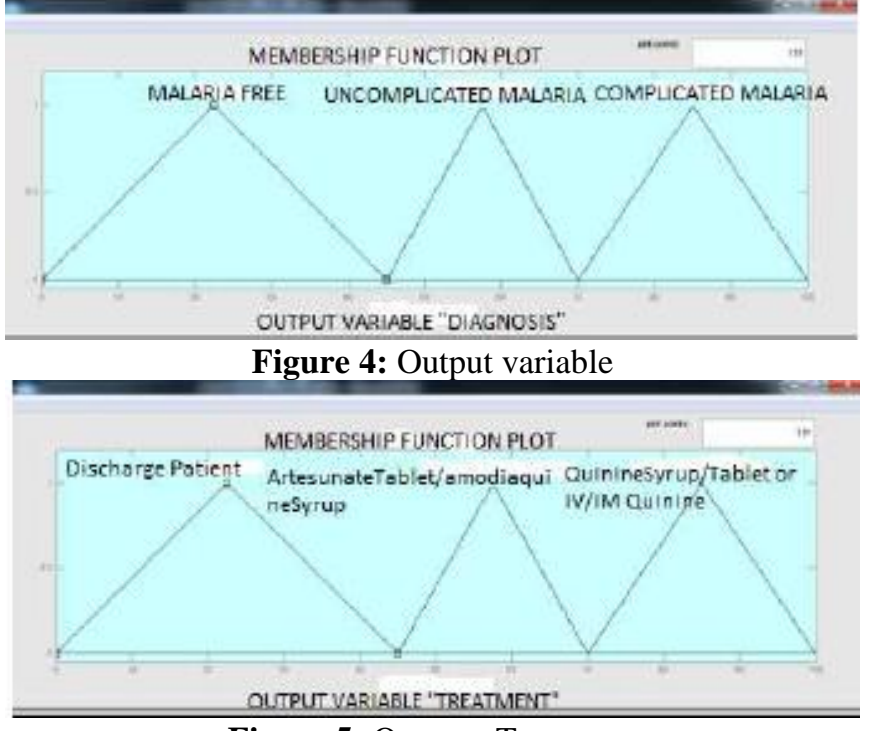

Figure 5: Output: Treatment

\section{The Algorithm}

1. Type patients ID;

2. If the ID is available in the data base;

Then read (name, age, gender);

Else type name, age and gender;

3. Type (temperature, weight, height, pulse rate);

4. Calculate $\mathrm{BMI}=$ weight/ (height) 2 ;

5. Evaluate the symptoms against the fuzzy logic syntax in the knowledgement base;

Select appropriate variables for the symptoms' input variable and construct fuzzy logic membership function; Create fuzzy logic decision matrix (syntax) as the knowledge base of the system; match input variable to the fuzzy logic syntax in the knowledge base; Determine whether malaria;

6. If malaria

Then prescription a druggist based on the case of infection;

Else Give "malaria free" as message;

7. Stop.

\section{Results}

\begin{tabular}{|c|c|c|c|}
\hline $\begin{array}{c}\text { Patients } \\
\text { ID }\end{array}$ & $\begin{array}{c}\text { Medical Doctors } \\
\text { Diagnosis }\end{array}$ & $\begin{array}{c}\text { Laboratory } \\
\text { Diagnosis } \\
\text { Designed }\end{array}$ & $\begin{array}{c}\text { Algorithm } \\
\text { Diagnosis }\end{array}$ \\
\hline 001 & Uncomplicated malaria & Malaria free & Malaria free \\
\hline 002 & Malaria free & $\begin{array}{c}\text { Uncomplicated } \\
\text { malaria }\end{array}$ & $\begin{array}{c}\text { Uncomplicated } \\
\text { malaria }\end{array}$ \\
\hline 003 & Uncomplicated malaria & $\begin{array}{c}\text { Uncomplicated } \\
\text { malaria }\end{array}$ & $\begin{array}{c}\text { Uncomplicated } \\
\text { malaria }\end{array}$ \\
\hline
\end{tabular}

Used laboratories of parasite diagnosis as a standard to compare, percentage accuracy was measure as: (Correct diagnosis) (Total diagnosis) $\times 100$, in compare, the percentage accurate of medical doctors' diagnosis is solely based on guess work when a doctor makes malaria parasite diagnosis by observed and conversed with patients. The designed parasite diagnosis algorithm is based on scientific approach because get parasite malaria were measured using scientific measuring instruments and standard SI units. 


\section{International Journal of Science and Research (IJSR) \\ ISSN (Online): 2319-7064}

Index Copernicus Value (2013): 6.14 | Impact Factor (2015): 6.391

\section{Conclusion}

Accurate medical parasite diagnosis is one of the major methods to sustain good health and long live. It is a very useful tool in dealing accurate, solve problems that appear to be solved only by human when data is modeled well. The hospitals will get enough storage media to saving the database of medical reports of patients to serve a patient's patient's medical history for future. This database can be referenced among health facilities. It provides method of parasite diagnosis with so much accurate and reduces the hours spent by patients in a hospital.

\section{References}

[1] Ademola, O. P. (2007). Fuzzy-Wavelet Method for Time Series Analysis. PhD Thesis submitted to the department of Computing, School of Electronics and Physical Sciences, University of Surrey, Guildford, Surrey, UK

[2] Adekoya, A.F; Akinwale, A.T and Oke, O.E. (2008). A medical expert system for managing tropical diseases. Proceedings of the third conference on Science and National Development, COLNAS, pp 74-86

[3] Beth, A. S, Claudio, A. N, Burhan, I. T. (2002). Fuzzy pharmacology: theory and Applications. Trends in Pharmacological Sciences Vol.23 No.9 September 2002

[4] Cengiz Kahraman, Murat Gulbay and Ozgur kabak (2006) Application of Fuzzy sets in Industrial Engineering

[5] Eesha Duggal (2011). Types of malaria. Onlymyhealth editorial team

[6] Ekong, V.E., Onibere, E.A., Imianvan, A.A (2011). Fuzzy Cluster Means System for the Diagnosis of Liver

[7] Djam, X. Y, Wajiga, G. M, Kimbi Y. H, and Blamah, N. V (2011). A Fuzzy Expert System for the Management of Malaria. International Journal of Pure and Applied Sciences and Technology (5(2) (2011), pp. 84-108

[8] Djam, X. Y and Kimbi Y. H (2011). A Decision Support System for Tuberculosis Diagnosis.The Pacific Journal of Science and Technology, Volume 12. Number 2. November 2011.

[9] Imianvan, A. A and Obi J, C (2012). Cognitive analysis of multiple sclerosis utilizing fuzzy cluster means. International Journal of Artificial Intelligence \& Applications (IJAIA), Vol.3, No.1, January 2012

[10] Imianvan A.A. and Obi J.C. (2011). Diagnostic evaluation of hepatitis utilizing fuzzy clustering Means. World Journal of Applied Science and Technology, Vol.3. No.1 (2011). 23-30

[11] Imianvan A. A., Anosike U.F, Obi J. C. (2011). An Expert System for the Intelligent Diagnosis of Hiv Using Fuzzy Cluster Means Algorithm. Global Journal of Computer Science and Technology Volume 11 Issue 12 Version 1.0 July 2011

[12]Lotfi A. Zadeh (1994). Fuzzy Logic, Neural Networks, and Soft Computing. Communication of the ACM, March 1994, vol37, no 3, pp. 77-83

[13] Mehdi sotudeh C, Mohammad R, Majid M (2010). A novel soft computing approach to component fault detection and isolation of $\mathrm{cnc} \mathrm{x}$-axis drive system.
Intelligent automation and soft computing, vol. 16, no. 2, pp. 177-191, 2010.

Volume 5 Issue 6, June 2016 www.ijsr.net 